\title{
Discrete element modelling of a rock cone crusher
}

Authors: Huiqi Li, Faculty of Engineering, University of Nottingham, NG7 2RD, UK. Email: lihuiqireal@gmail.com

Phone: 00441158544377

Glenn McDowell, Faculty of Engineering, University of Nottingham, NG7 2RD, UK;

Ian Lowndes, Faculty of Engineering, University of Nottingham, NG7 2RD, UK.

\begin{abstract}
The feasibility of the discrete element method to model the performance of a cone crusher comminution machine has been explored using the particle replacement method (PRM) to represent the size reduction of rocks experienced within a crusher chamber. In the application of the PRM method, the achievement of a critical octahedral shear stress induced in a particle was used to define the breakage criterion. The breakage criterion and the number and size of the post breakage progeny particles on the predicted failure of the parent particles were determined from the results of an analysis of the experimental data obtained from diametrical compression tests conducted on series of granite ballast particles. The effects of the closed size setting (CSS) and eccentric speed settings on the predicted product size distribution compare favourably with the available data in the literature.
\end{abstract}

\section{Introduction}

The cone crusher is the most common type of mineral comminution machine that is used widely in the minerals and aggregates extractive industries to crush medium or above medium sized rocks. Although the operational design of cone crushers has experienced a significant improvement since the first models were developed in the mid-1920s, further improvements to the development of crusher 
design to enhance performance have been restricted due to a number of factors. Firstly, it has proved difficult to successfully predict the size distribution and shape of the crusher product for a given feed stream. A number of researchers have proposed a series of iterative empirical models based on experimental observation (Gauldie, 1953; Whiten, 1972; Evertsson, 1997). These inverse solution methods attempt to match the size distributions of the feed and product streams. However, to date engineers have been unable to adapt these models to assist in the development of modified crusher chamber design configurations to improve the operational performance of these machines. In particular, these iterative inverse solution models do not allow the design engineer to investigate the influence that changes to the cavity profile, the cone throw or rotational speed settings may have on the crusher performance. The use of an incremental build and testing of alternative design prototypes is expensive, often requiring the production and several models to identify an economic improvement in the crusher performance. The development of a validated computational simulation mode of a cone crusher could significantly reduce the required lead time and costs. The discrete element method (DEM) (Cundall and Strack, 1979) provides a potential method to investigate the mechanical behaviour of the flow and breakage of granular material on both the micro and macro scales. Over the past thirty years, DEM models have been widely used to investigate the mechanical behaviour of granular material. In recent years, the particle replacement method (PRM) has been widely used to model particle breakage using DEM. The PRM approach replaces the predicted failed parent particle by a number of new and smaller fragments. The achievement of a critical octahedral stress induced in a particle was used as the breakage criterion (McDowell and De Bono, 2013) in the application of the PRM method. The breakage criterion and breakage function were determined from the results of a series of experimental compression tests performed on a feed of different sizes granite rock samples. For a given particle feed size distribution, the performance of the computational crusher model was validated by evaluating the effects that changes to the CSS and eccentric speed settings had on the predicted product size distribution. Alternative breakage functions were also examined to study their influence on the computed product size distributions. 


\section{The construction of DEM cone crusher model}

Figure 1 and Figure 2 illustrate typical vertical and horizontal cross sectional views through a cone crusher. To construct a representative numerical DEM model of a cone crusher, the geometry of a crusher was defined by the specification of the following eight parameters. The location of these parameter measurements are shown on Figure 1and Figure 2.

- The width of feed entrance to the crusher chamber, $F$.

- The closed size setting (CSS): the smallest distance between concave and mantle.

- The throw $s$ : this represents the eccentric distance the cone moves during a half rotation

- The bite angle $\beta$ : the angle subtended between the concave and the mantle.

- The cone angle $\alpha$, measured as the angle at the base of the mantle.

- The eccentric angle $\gamma$ : the angle of the eccentric rotation of the cone.

- The parallel length of the cone $\Delta l$ : the length of the lower part of the concave that is parallel to the mantle in CSS state.

- Bottom diameter of the mantle $\mathrm{D}_{\mathrm{c}}$.

As the simulated operation of the DEM cone crusher with a real geometry is computationally too expensive, the performance of a small scale cone crusher was modelled in this study. The dimensions of the model parameters were determined based on the full scale cone crusher design geometry presented by Lang (1998). Table 1 gives the values of these parameters.

Table 1. Parameter values used to construct the DEM cone crusher model

Figure 1. A vertical cross-section view through a typical cone crusher.

Figure 2. A horizontal cross-section view through a typical cone crusher 
The mantle was modelled by a cylinder wall, and the concave was represented by two cylinder walls of which the lower one was used to model the part of the concave which is parallel to the mantle. The calculation procedures of geometrical parameters were listed in Table 2 and these parameters are illustrated in Figure 3.

Table 2. Calculation procedures of geometrical parameters of prototype cone crusher

\section{Figure 3. Parameters calculated in the DEM cone crusher model}

The proprietary DEM code $\mathrm{PFC}^{3 \mathrm{D}}$ (Itasca, 2008) was used to construct and solve the simulation models described in this study. Figure 4 shows an illustration of the representative 3D rendered surfaces of the mantle and concaves formed within a typical DEM cone crusher model. The motion of the cone has two components: an eccentric pendular angular velocity $\omega_{e \sigma o}$ about the vertical axis of the cone crusher, and a 'spinning' angular velocity of the cone about its own axis $\omega_{\text {spin }}$, related to $\omega_{\theta c c}$ by:

$$
\omega_{\text {spin }}=\frac{R_{\text {bot }_{m}}+s}{R_{\text {bot } m}} \omega_{\theta c c}
$$

\section{Breakage criterion}

The PRM approach has recently been used by Lichter et al (2009) to model the rock fracture predicted within a cone crusher. However, in that study the rock particles were described by polyhedral models and the fracture criterion and the parameters used to determine the distribution of the resultant post breakage fragment sizes were not discussed. A number of other researchers have proposed a number of other breakage criteria using the PRM approach. For example, Tsoungui et al.(1999) proposed a 
measure of shear stress in two dimensions. Astrom \& Herrmann(1998) and Ben-Num \& Einav(2010) used a measure of compressive stress to define a two dimensional fracture criterion. McDowell \&de Bono(2013) and McDowell et al(2013) suggested the use of the octahedral shear stress as the fracture criterion for a three dimens ional simulation of rock failure. It was decided to employ the octahedral shear stress breakage criterion for the simulations performed in this study. This model was selected as it avoids partic le fracture under a high hydrostatic stress but low deviatoric stress, e.g., if a partic le is subjected to diametrical point loads, equal in three mutually orthogonal directions then it would not break under this hydrostatic stress $q=0$ (McDowell and De Bono, 2013). The octahedral stress is expressed as:

$$
q=\frac{1}{3}\left[\left(\sigma_{1}-\sigma_{2}\right)^{2}+\left(\sigma_{1}-\sigma_{3}\right)^{2}+\left(\sigma_{3}-\sigma_{2}\right)^{2}\right]^{1 / 2}
$$

where $\sigma_{1}, \sigma_{2}$ and $\sigma_{3}$ are the principle stresses in three directions. Therefore the assumption was made that, for the rock particles flowing and be ing successively compressed as the cone rotates in the chamber, the particles would be replaced if the computed octahedral shear stress exceeded its 'strength'. However, $q$ is difficult to measure in experiments so it is difficult to calibrate the strength of the partic le. For a sphere, McDowell et al (2013) related the octahedral shear stress $q$ to the tensile strength $\sigma$ measured from a diametrical compression test by:

$$
q=0.9 \sigma
$$

Equation 3

where $\sigma$ is the tensile stress at failure which is defined by McDowell and Bolton (1998):

$$
\sigma=\frac{F}{d^{2}}
$$

and $F$ is the diametrical compressive force applied by the platens and $d$ is the diameter of the sphere.

The Weibull (1951) statistical distribution is one of the most commonly used tools to describe the fracture of disordered materials and has been applied to a wide range of granular materials: ceramics (Davidge, 1979); soil particles (McDowell \& Amon, 2000;) and the analysis of survival data 
(Mudholkar, 1996). Therefore in this study the rock particles were given strengths for a given size described by a Weibull distribution. The average tensile strength, $\sigma$, is also related to the partic le size (Bazant, 1984; Lee, 1992; McDowell and Bolton, 1998; Bui, 2005). Consequently, a size effect factor $b$ is also applied to the particle strengths based on the assumption that particles have the same Weibull modulus for all the size fractions, which is described by the expression:

$$
q_{o} \propto \sigma_{a v} \propto d^{b}
$$

Equation 5

where $q_{o}$ denotes the $37 \%$ strength for a size $d, \sigma_{f}$ is the average tensile strength and $b$ is the size effect factor which is constant for a given material.

\section{Experimental calibration}

In order to calibrate the tensile strength, $q$, of the particles, the tensile strengths of three size fractions of Glensanda ballast particles were determined from the execution of a series of experimental diametrical compression tests: $14-28 \mathrm{~mm}, 30-37.5 \mathrm{~mm}$ and $40-60 \mathrm{~mm}$. Thirty particles of each size fraction were tested; the experimental rig used is as shown in Figure 5.

Figure 5A photograph of the Zwick experimental testing rig used to apply diametrical compression tests to selected rock samples.

To quantify the ballast particle strengths using Weibull (1951) statistics, the tensile strengths (calculated from equation 12) of each size fraction were ranked in ascending order to compute the survival probability (Davidge, 1979) for each tensile stress at failure, the survival probability was computed using the mean rank position equation:

$$
P_{S}=1-i /(N+1)
$$

where $i$ is the ith ranked sample from a total of $N$ samples. Thus, given the test results for 30 same sized particles, the lowest value of $\sigma$ gives a particle survival probability of $30 / 31$, and the tensile strength of the strongest particle gives a particle survival probability of $1 / 31$. Assuming the particle 
strengths obey a Weibull distribution, the survival probability of particles of size $d$ under a tensile stress $\sigma$ is given by:

$$
P_{S}(d)=\exp \left(-\left(\frac{\sigma}{\sigma_{o}}\right)^{m}\right)
$$

where $m$ is the Weibull modulus and $\sigma_{0}$ is the tensile stress such that $37 \%$ of the particles survive, commonly termed the $37 \%$ tensile strength' of the sample. The Weibull modulus determines the coefficient of variation, which reduces as the variability in strength increases. Equation 15 may be recast in the form:

$$
\ln \left[\ln \left(\frac{1}{P_{S}(d)}\right)\right]=\min \left(\frac{\sigma}{\sigma_{o}}\right)
$$

The Weibull modulus $m$ and the $37 \%$ tensile strength for each set of tests may be graphically determined from a Weibull survival probability plot, which is a plot of $\ln \left(\ln \left(1 / p_{s}\right)\right)$ against $\ln \sigma$. The Weibull modulus $m$ corresponds to the slope of the line of best fit, and the value of $\sigma_{o}$ is the value of $\sigma$ when $\ln \left[\ln \left(\frac{1}{P_{s}(d)}\right)\right]=0$. The Weibull probability of plots for the three tested size fractions of ballast particles are plotted in Figure 6

It is clear that the measured tensile strengths of all of three tested size fractions of the ballast exhibit a Weibull distribution Table 3 shows summary of the measured experimental data for all three size fractions: the $37 \%$ tensile strength $\left(\sigma_{o}\right)$, the average tensile strength $\left(\sigma_{f}\right)$, correlation coefficient of linear fit $\left(R^{2}\right)$, and the Weibull modulus $(m)$. 
Table 3 S ummary of the averages of the measured experimental data obtained from the sets of single sized particle crushing tests

Figure 7 shows a plot of the average particle strength as a function the particle size. The data can be expressed as the equation:

$$
\sigma_{a v}=480.03 d^{-1.1}
$$

Figure 7 Average tensile strength against average particle size at failure

To select an appropriate breakage function for the construction of a PRM model to simulate the breakage behaviour experienced in a cone crusher chamber model, the size distribution of the daughter fragments resulting from the failure of the single parent particles were analysed. Figure 8 shows the typical fragments generated following the failure of the single particles. As may be observed, the failed particles typically formed 2 or 3 larger sized progeny partic les accompanied by a few smaller sized partic les and some fines.

Figure 8 Photographs showing the typical daughter fragments produced following the failure of the single parent particles subjected to a diametrical compression test

Twenty particles of a total of thirty particles of each size fraction were sieved. For each original parent particle, the daughter fragments were sized according to their sieve size and then the individual size fractions individually weighed. The minimum sieve size used was $8 \mathrm{~mm}$, thus all fragments smaller than $8 \mathrm{~mm}$ were classified as fines. It was found that for all the size fractions, the largest daughter fragments can in most cases form approximately $60 \%$ of the original particle mass. The second largest progeny fragments have a mass of approximately $30 \%$ of the original parent particle. The remaining fragments tend to be formed by a collection of much smaller particles and fines that represent less than $10 \%$ of the original partic le mass. Figure 9 shows the size classification analyses of 
ten samples of each size fraction. Therefore, it was proposed to adopt the following protocol to govern the generation of daughter particles on the application of a diametrical compression to each size of original particle: once the critical tensile strength of this size of particle is exceeded, the particle will always divide into two major particles which will be $60 \%$ and $30 \%$ of the original particle mass, with the remaining mass $(10 \%)$ is a small fragment representing the remaining crushed fines in the aggregate.

Figure 9A graphical presentation of the size and mass dassification data obtained from analyses performed on the fragments produced on the failure of particles subjected to a diametrical compression test

\section{Input parameters}

A simple sphere was used to present the particle in this research. The contact model used here is the linear contact model (Itasca, 2008). To permit a tractable computational time two hundred particles were chosen to represent the feed material. The size of the feed material needs to be chosen from the size range of the experimentally crushed ballast particles as the experimental results of the tensile strengths are necessary to calibrate the rock breakage criteria in the DEM model. The smallest size fraction $14-28 \mathrm{~mm}$ was chosen as the size range of the feed material. Therefore the feed particles are 200 spheres with a random diameter of between $14 \mathrm{~mm}\left(\sigma_{\circ}=38.6 \mathrm{MPa}\right)$ and $28 \mathrm{~mm}\left(\sigma_{\circ}=18.2 \mathrm{MPa}\right)$.

Table 4 shows the input parameters for the model. The particle stiffness were calculated by the equation given by Itasca Consulting Group, Inc (2008), which is the Young's modulus of the material $E_{e}$ to the radius of the balls $R$ and stiffness:

$$
k_{n}=k_{s}=4 R E_{c}
$$

A typical value of the Young's modulus for the Glensanda granite ballast was determined to be 70GPa. The interparticle friction in this study was chosen to be the same as that for simulations on aggregates of ellipsoidal pebbles (McDowell et al, 2011) this was determined to achieve the same 
angle of repose in the DEM simulation as that measured for the real pebbles during the execution of a simple slump test in the laboratory. This assumption was made, because using spheres to represent rocks, it will be very difficult to achieve an angle of repose similar to ballast aggregate, the reader is referred to McDowell et al (2011) for details of the modelling of flow of ellipsoidal rocks. Energy dissipation at contacts was modelled by the viscous damping model (Itasca, 2008) characterized by the critical damping ratio (Ginsberg\& Genin, 1984). The critical damping ratio was calibrated by comparing the results of model simulation drop tests with corresponding laboratory drop tests - that is individual pebbles were dropped onto the bottom wall. The reader is referred to the work of McDowell et al (2011) for the details of the determination of particle-particle friction coefficient and critical damping ratio. The minimum size of the breakable spheres was set at a diameter of $4 \mathrm{~mm}$. The minimum particle size was defined to control the time step of the DEM calculation, the maximum number of partic les and thus the computational time.

The Weibull modulus of particle strengths for a given size was set as the average value of the three size fractions: 2.95 . The size effect factor $b$ in equation 12 was determined as -1.1 based on the Figure 7.

Table 4 Input parameters of the cone crusher model for PRM approach

\section{Breakage functions}

Based on the size distributions of the broken rock particles produced by the laboratory diametrical compression tests described above, an original particle is assumed to split into three particles which individually represent $60 \%, 30 \%$ and $10 \%$ of the mass of the original particle. To conserve mass, the three progeny fragments were sufficiently overlapped to be contained within the bounding parent sphere. The axis joining the centres of the three new spheres was aligned along the direction of the minor principal stress, as shown in Figure 10. This overlap causes the particle fragments to move along the direction of the minor principal stress of the original parent particle, as would occur when a single particle is compressed between two flat parallel platens (McDowell \& De Bono, 2013). 
However, huge undesirable local pressure spikes were generated by the overlaps of fragments in the size distribution function. The imposed elastic energy caused by the overlap needs to be accommodated after every update of particle breakages. Otherwise, all the fragments will break infinitely under the artificial created huge pressure. In order to accommodate this problem, the author defined a 'freeze state' to release the artificial energy. The cone crusher model will be set into the freeze state once breakage occurs with the follow ing assumptions:

- When new particles are generated, all other particles are initially given zero rotational and translational velocities. The locations of the boundaries (the walls of the crusher model) are fixed.

- In this state, all of the particles are temporarily assigned an artificially large mass $\left(3 \times 10^{9}\right.$ $\mathrm{kg} / \mathrm{m}^{3}$ ) to minimise the motions caused by collision.

- The new particles are given an artificially low stiffness $\left(1 \times 10^{3} \mathrm{~N} / \mathrm{m}\right)$ to minimise the energy release generated by the overlaps.

- The viscous damping system is removed and a high local damping coefficient 0.9 (Itasca, 2008) is added to accelerate the stabilization of the new particles.

- Gravity is removed.

A flow chart illustrating the solution stages of the cone crusher model is shown in Figure 11. The particles in the crusher chamber will continue to flow until a breakage condition is achieved. At this point, the solution algorithm applies the 'freeze' state until the artificial energy of the new fragments is released and dissipated. Thereafter, the model reverts to the normal state allowing the particles to continue to flow. It should be noted that the instantaneous velocities of all particles are recorded before the system applies a freeze state, after which these velocities are returned to the original 
unbroken particles It is noted that a local damping system was replaced in the model by a viscous damping system, when the solution algorithm reverts from the freeze s to the normal state.

Figure 11 Flow chart of the cone crusher solution algorithm using the PRM model approach

\section{Simulation procedure}

Figure 12 shows snapshots of the crusher simulation in action. In industry the feed material is usually loaded to the crusher feed bin by a hydraulic shovel or by a conveyer belt. This material is then ideally choke fed under gravity into the top of the cone crusher chamber. It is difficult to entirely replicate this complex feed process within the model, and thus the feed is simplified by assuming that the feed particles flow from a full bin located vertically above the crusher chamber. The computational algorithm is detailed as follows:

- 200 particles are randomly generated inside an artificial cylinder wall 1 , representing the feed bin (labelled in Figure 12).

- The spheres representing the feed material are deposited by the gravity into the feed bin. A flat artificial wall 2 (labelled in Figure 12) is constructed above the concave to avoid the particles from dropping directly through the chamber.

- The flat artificial wall 2 is then deleted to let the particles to flow under gravity through the top of the crusher chamber. A conical artificial wall 3 (labelled in Figure 12) was constructed to cap the top of the mantle, and this prevents any partic les from flowing into the hollow mantle.

- The mantle is rotated.

Figure 12 A sequence of animation stills which represent the dynamic performance of the crusher predicted by the DEM model 


\section{Model validation}

The influence of changing the CSS and eccentric speed on the size distribution of the products was first studied. Figure 13 shows the product size distributions generated by the model for various CSS for a fixed eccentric speed of rotation of $300 \mathrm{rpm}$. From an examination of these results it is clear that the feed particles will experience greater size reduction as the CSS decreases. Figure 14 shows the computed product cumulative size distribution curves for a range of eccentric rotational speeds values, at a constant CSS (15mm). It is shown that the upper size distribution curve represent the simulation with higher eccentric speed. That means the faster the mantle rotates, the larger the number of breakages which will occur in the chamber. It is concluded that the effect of both CSS and eccentric speed are monotonic in the product size distribution: either higher eccentric speed or smaller CSS lead to greater size reduction for the feed particles. This is qualitatively consistent with the experimental results in the literature Hulthen (2010).

Figure 13 The effect of CSS on the size distribution of the products predicted by the DEM simulation

Figure 14The effect of eccentric speed on size distribution of the size distribution of the products predicted by the DEM simulation

\section{Influence of breakage mechanism}

Figure 15 shows the effect of the breakage mechanism on the computed product cumulative size distributions generated by two alternative breakage algorithms. The first mechanism is the triple-split mechanism that has been used so far. The second mechanism is a simpler equal-split mechanism such that the two fragments are of equal size, contained within the parent sphere when fracture occurs, and such that the fragments move along the axis of the minor principal stress, with conservation of mass as shown in Figure 16. The parameters are those in Table 4. The CSS was set at $15 \mathrm{~mm}$ and the eccentric speed was $300 \mathrm{rpm}$. It can be seen the cumulative mass curves of particles larger than $6 \mathrm{~mm}$ nearly overlap. The major difference occurs at the bottom of the curve which represents the 
cumulative mass of the fine particles. The equal split mechanism mass distribution curve suddenly changes at a particle size of $5 \mathrm{~mm}$, such that only a few fine particles are generated. The difference between the two curves for smaller particle sizes is likely to be due to the comminution limit - the smallest particle size which can break is $4 \mathrm{~mm}$. For such a particle the triple-split mechanism would result in a much smaller size for the smallest fragment. In addition, the triple split mechanism will give a large number of different discrete particle sizes over several generations of fracture, whereas for the double split mechanism a much smaller number of discrete fragment sizes are possible.

Figure 15 The effect of the breakage function on the size of the rock fragments formed

\section{Figure 16 Equal split mechanism}

All the particle strengths are governed by a $37 \%$ strength, $\sigma_{\odot}$, the size effect factor, $b$, and the Weibull modulus $m$. Model simulations using various values of these three parameters have been performed with the triple-split mechanism to investigate their effect on the predicted cumulative size distribution of the products. Figure 17 shows the effect of changing the $\sigma_{\circ}$ parameter, for a constant $b$ of -1.1 and constant $m$ of 2.65. It can be observed that the predicted solution curves nearly overlap when $\sigma_{o}$ varies from 10MPa to 20MPa. However, if $\sigma_{\circ}$ is increased or decreased by a factor of 10 , to values of 80or $0.8 \mathrm{MPa}$, respectively it is clear that more size reduction occurs at lower values of $\sigma_{\odot}$. 
Figure 18 shows a plot of the computed particle strengths as a function of particle size for various values of $b$. For similarly sized fragments, an increase in the magnitude of $b$ results in a higher strength; that is to say: $b$ controls the hardening law and a higher value means a stronger size effect on strength. Figure 19 shows the cumulative particle size distribution as a function of the size effect factor $b$ using the triple-split mechanism. It is evident that increasing the magnitude of $\mathrm{b}$ results in less breakage in the crusher chamber.

Figure 18 Particle strengths as a function for various values of the parameter $b$ with initial particle strength $18 \mathrm{Mpa}$

Figure 19 The effect of the parameter $b$ on the size distribution of products

Figure 20 shows the influence that changes to the value of the Weibull modulus parameter $m$ have on the cumulative product size distribution, for a constant value of $b=-1.1$ and $\sigma_{0}=18 \mathrm{MPa}$ for the largest particle size. The three curves for the different Weibull modulus $m$ values are almost coincident. It is therefore concluded that changes to the Weibull modulus parameter does not significantly affect the product cumulative size distribution. In conclusion, for the three parameters which govern the particle strengths, size effect factor $b$ has the greatest influence to the product size distribution and Weibull modulus $m$ has the least influence.

Figure 20The effect of the parameter $m$ on the size distribution of products

\section{Conclusions}

A prototype DEM cone crusher model has been successfully modelled using the PRM approach and it has been validated against existing experimental data in the literature. The performance of these crusher models was assessed by examining the influence that changes to the CSS and eccentric speed 
settings have on the predicted cumulative product size distributions. It was found either a decrease in the CSS or an increase in the eccentric rotational speed resulted in more computed breakage events within the crusher chamber, which is consistent with the experimental data in literature. The breakage mechanism was also found to influence the cumulative size distribution of the products for smaller fragment sizes. Three parameters were identified as characterising the strength of particles: the $37 \%$ tensile strength $\sigma_{\odot}$, the size effect factor $b$ and the Weibull modulus $m$. The size effect factor $b$ is

found to have most influence on the product cumulative size distribution, whilst changes to the Weibull modulus $m$ had little effect for this relatively unconstrained process. It can be concluded that the simple PRM model may be very useful in quickly establishing the influence that changes to the parameter values may have on the predicted cone crusher performance, thus informing the design of new more efficient prototypes.

\section{References}

Astrom, J. A. and Herrmann, H. J.(1998). Fragmentation of grains in a two-dimensional packing. Eur. Phys. J. B5, No. 3, 551-554

Bazant, Z. P. (1984). Size effect in blunt fracture: concrete, rock, metal. Journal of Engineering Mechanics, 110(4), 518-535.

Ben-Nun, O., \& Einav, I. (2010). The role of self-organization during confined comminution of granular materials. Phil. Trans. R. Soc. A, 231-247.

Bui, D. D., Hu, J., \& Stroeven, P. (2005). Particle size effect on the strength of rice husk ash blended gap-graded Portland cement concrete. Cement and concrete composites, 27(3), 357-366.

Cundall, P. \& Strack, O. (1979). A discrete numerical model for granular assemblies, Geotechnique, 29(1) $47-65$

Davidge, R.W. (1979). Mechanical behaviour of ceramics. Cambridge University Press. 
Evertsson, C.M. (1997) Prediction of Cone Crusher Performance, Lic. Eng.Thesis, Machine and Vehicle Design, Chalmers University of Technology, January 17, 1997

Gauldie, K. (1953) Performance of Jaw Crushers, Engineering, 456-458, October 9, 485-486, October 16,1953

Ginsberg, H.H., and Genin, J. (1984) Dynamics, Second Edition. New York: John Wiley and Sons.

Herbst, J. A., Lo, Y. C., \& Flintoff, B. (2003). Size reduction and liberation. Principles of Mineral Processing, MC Fuerstenau and KN Han (eds.), Society of Mining, Metallurgy and Exploration, Littleton, $\mathrm{CO}, 61-118$.

Hulthen, E. (2010). Real-time optimization of cone crushers. PhD thesis. Chalmers University of Technology.

Itasca Consulting Group (2008), Inc. $P F C^{3 D}$ (Particle Flow Code in Three Dimensions), version 3.0. Minneapolis: ICG.

Lang, B.X. (1998) The Cone Crusher (first ed.)Mechanical Industry Publishing Company, Beijing Lee, D. M. (1992). The angles of friction of granular fills. PhD dissertation, University of Cabridge Lichter, J., Lim, K., Potapov, A., \& Kaja, D. (2009). New developments in cone crusher performance optimization. Minerals Engineering, 22(7), 613-617.

Lobo-Guerrero, S. \& Vallejo, L. E. (2005). Crushing a weak granular material: experimental numerical analyses. Geotechnique55, No. 3, 245-249,

McDowell, G. R., \& Amon, A. (2000). The application of Weibull statistics to the fracture of soil particles. Soils and foundations,40(5), 133-141.

McDowell, G.R. and Bolton, M.D. (1998). On the micro mechanics of crushable aggregates. Geotechnique 48, No. 5, 667-679 
McDowell, G.R., Li, H. and Lowndes, I. (2011) The importance of particle shape in discrete element modelling of particle flow in a chute. Geotechnique Letters 1, No. 3, 59-64.

McDowell, G., \& de Bono, J. P. (2013). On the micro mechanics of one-dimensional normal compression.Geotechnique,63.Volume 63, Issue 11,895-908

McDowell, G.R., de Bono, J.P., Yue, P and Yu, H-S. (2013) Micro mechanics of isotropic normal compression. Geotechnique Letters 3, 166-172. doi: 10.1680/geolett.13.00050.

Mudholkar, G. S., Srivastava, D. K., \& Kollia, G. D. (1996). A generalization of the Weibull distribution with application to the analysis of survival data. Journal of the American Statistical Association, 91(436), 1575-1583.

Tsoungui, O., Vallet, D., \& Charmet, J.-C. (1999). Numerical model of crushing of grains inside two dimensional granular materials. Powder Technology, 190-198.

Weibull, W. (1951). A statistical distribution function of wide applicability. J.Appl. Mech. 18, pp. 293-297

Whiten, W.J.(1972) Simulation and model building for mineral processing. PhD Thesis, University of Queensland (JKMRC) 
Table 1. Parameter values used to construct the DEM cone crusher model

\begin{tabular}{|l|l|l|l|l|l|l|l|}
\hline$F(\mathrm{~mm})$ & $\mathrm{CSS}(\mathrm{mm})$ & $s(\mathrm{~mm})$ & $\beta\left(^{\circ}\right)$ & $\alpha\left(^{\circ}\right)$ & $Y\left(^{\circ}\right)$ & $\Delta L(\mathrm{~mm})$ & $\mathrm{D}_{\mathrm{c}}(\mathrm{mm})$ \\
\hline 55 & $12-18$ & 4.5 & $18-22$ & 45 & 2 & 50 & 300 \\
\hline
\end{tabular}


Table 2: Calculation procedures of geometrical parameters of prototype cone crusher

\begin{tabular}{|c|c|}
\hline Geo metrical Para meter & Calculation Procedure \\
\hline $\begin{array}{l}\text { The distance from pivot to the centre } \\
\text { of the bottom of the mantle: } h\end{array}$ & $h=180 s /(2 \pi \gamma)$ \\
\hline $\begin{array}{l}\text { The length of the upper part of the } \\
\text { length of concave: } l_{\text {upper } \_c}\end{array}$ & $l_{\text {upper } \_c}=(F-c s s) / \sin \beta$ \\
\hline $\begin{array}{l}\text { The radius of the bottom end of the } \\
\text { mantle: } R_{\text {bot_m }}\end{array}$ & $R_{b o t_{-} m}=D_{c} / 2$ \\
\hline $\begin{array}{l}\text { The radius of bottom end of the lower } \\
\text { concave: } \mathrm{R}_{\text {bot_c }}\end{array}$ & $R_{b o t_{-} c}=\cos \gamma *\left(s+R_{b o t_{-} m}\right)+C S S * \sin ((\alpha-\gamma)$ \\
\hline $\begin{array}{l}\text { The radius of top end of the lower } \\
\text { concave: } R_{\text {mid _c }}\end{array}$ & $R_{\text {mid_c }}=R_{b o t_{-} c}-\Delta l * \cos (\alpha-\gamma)$ \\
\hline $\begin{array}{l}\text { The radius of top end of the upper } \\
\text { concave: } R_{t o p_{-} c}\end{array}$ & $R_{\text {top } \_c}=R_{\text {mid } \__{-}}-l_{\text {upper } \_} * \cos (\alpha+\beta-\gamma)$ \\
\hline $\begin{array}{l}\text { The radius of the top end of the } \\
\text { mantle: } R_{t o p_{-} m}\end{array}$ & $R_{t o p_{-} m}=\frac{R_{t o p_{\_} c}-\sin (\alpha-\gamma) * F}{\operatorname{Cos} \gamma *\left(s+R_{b o t \_m}\right)} * R_{b o t \_m}$ \\
\hline The side length of the mantle: $l_{m}$ & $l_{m}=(F-C S S) / \sin \beta$ \\
\hline $\begin{array}{l}\text { The coordinate of centre of bottom end } \\
\text { of lower concave: } O_{b o t} c\end{array}$ & $(0, \quad C S S * \cos (\alpha-\gamma), 0)$ \\
\hline $\begin{array}{l}\text { The coordinate of centre of top end of } \\
\text { the lower concave: } O_{\text {mid } \_} c\end{array}$ & $(0, \operatorname{csS} \leqslant \cos (\alpha-\gamma)+\Delta l \leqslant \sin (\alpha-\gamma), 0)$ \\
\hline $\begin{array}{l}\text { The coordinate of centre of top end of } \\
\text { the upper concave: } O_{\text {top }} c\end{array}$ & $\operatorname{css} \leqslant \cos (\alpha-\gamma)+\Delta l ; \sin (\alpha-\gamma)+\sin (\alpha+\beta-\gamma)=l_{2}$ \\
\hline $\begin{array}{l}\text { The coordinate of the centre of bottom } \\
\text { end of mantle: } O_{b o t} m\end{array}$ & $(\cos \gamma * s,-\sin \gamma * s, 0)$ \\
\hline $\begin{array}{l}\text { The coordinate of the centre of top end } \\
\text { of mantle: } O_{\text {top } \_m}\end{array}$ & 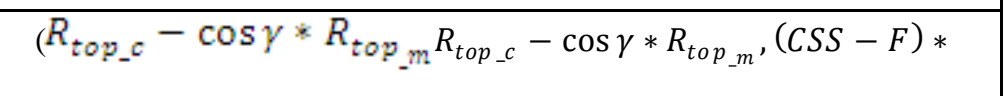 \\
\hline
\end{tabular}


Table 3 S ummary of the averages of the measured experimental data obtained from the sets of single sized particle crushing tests

\begin{tabular}{|l|l|l|l|l|}
\hline Particle size fraction & $37 \%$ tensile strength $\sigma_{o}$ & Average strength $\sigma_{f}$ & $R^{2}$ & Weibull Modulus $m$ \\
\hline $14-28 \mathrm{~mm}$ & $20.12 \mathrm{MPa}$ & $20.02 \mathrm{MPa}$ & 0.9608 & 3.0895 \\
\hline $30-37.5 \mathrm{~mm}$ & $12.61 \mathrm{MPa}$ & $11.26 \mathrm{MPa}$ & 0.9644 & 3.2859 \\
\hline $40-60 \mathrm{~mm}$ & $9.49 \mathrm{MPa}$ & $8.47 \mathrm{MPa}$ & 0.9882 & 2.4398 \\
\hline
\end{tabular}


Table 4 Input parameter of the cone crusher model for PRM approach

\begin{tabular}{|l|l|}
\hline Size effect factor $b$ & -1.1 \\
\hline Weibull Modulus $m$ & 2.65 \\
\hline$\sigma_{0,28 \mathrm{~mm}}$ & $18.2 \mathrm{MPa}$ \\
\hline$d_{o}$ & $28 \mathrm{~mm}$ \\
\hline Critical damping ratio & 0.11 \\
\hline Ball/wall friction & 0.37 \\
\hline Ball/ball friction & 0.37 \\
\hline Wall stiffness & $1 \mathrm{e} 13 \mathrm{~N} / \mathrm{m}$ \\
\hline Particle Young modulus & $70 \mathrm{GPa}$ \\
\hline Ball density & $2650 \mathrm{~kg} / \mathrm{m}^{3}$ \\
\hline
\end{tabular}




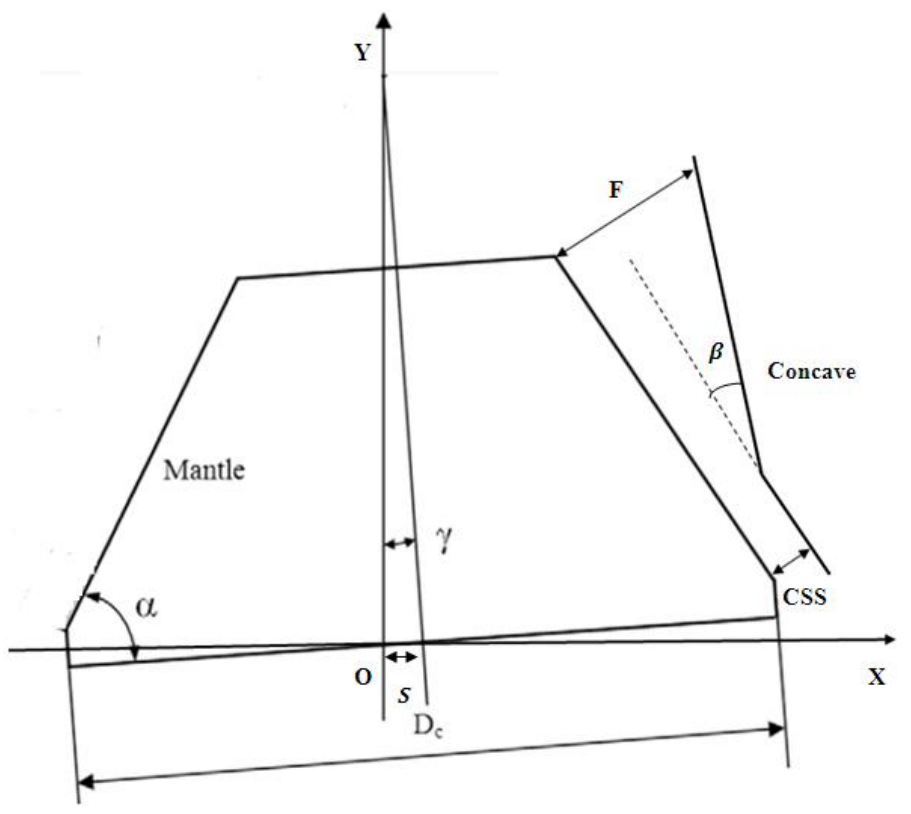

Figure 1. A vertical cross-section view through a typical cone crusher. 


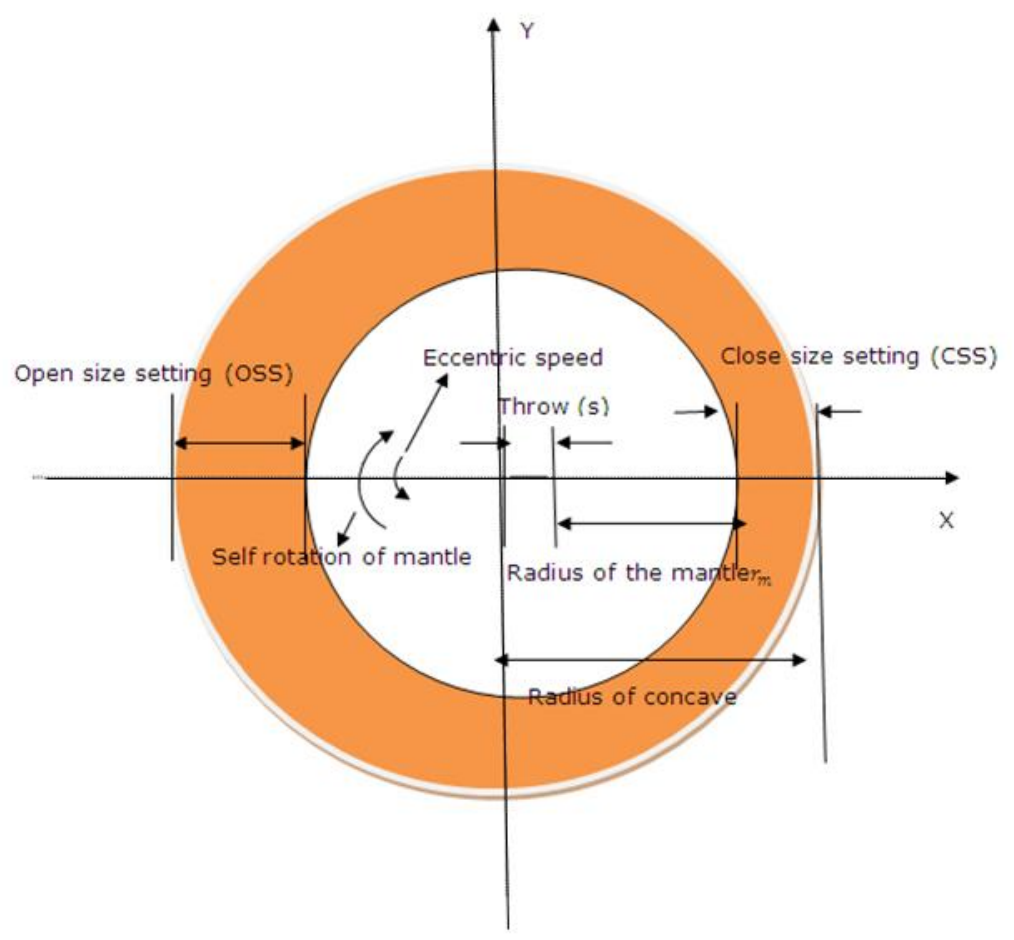

Figure 2. A horizontal cross-section view through a typical cone crusher 


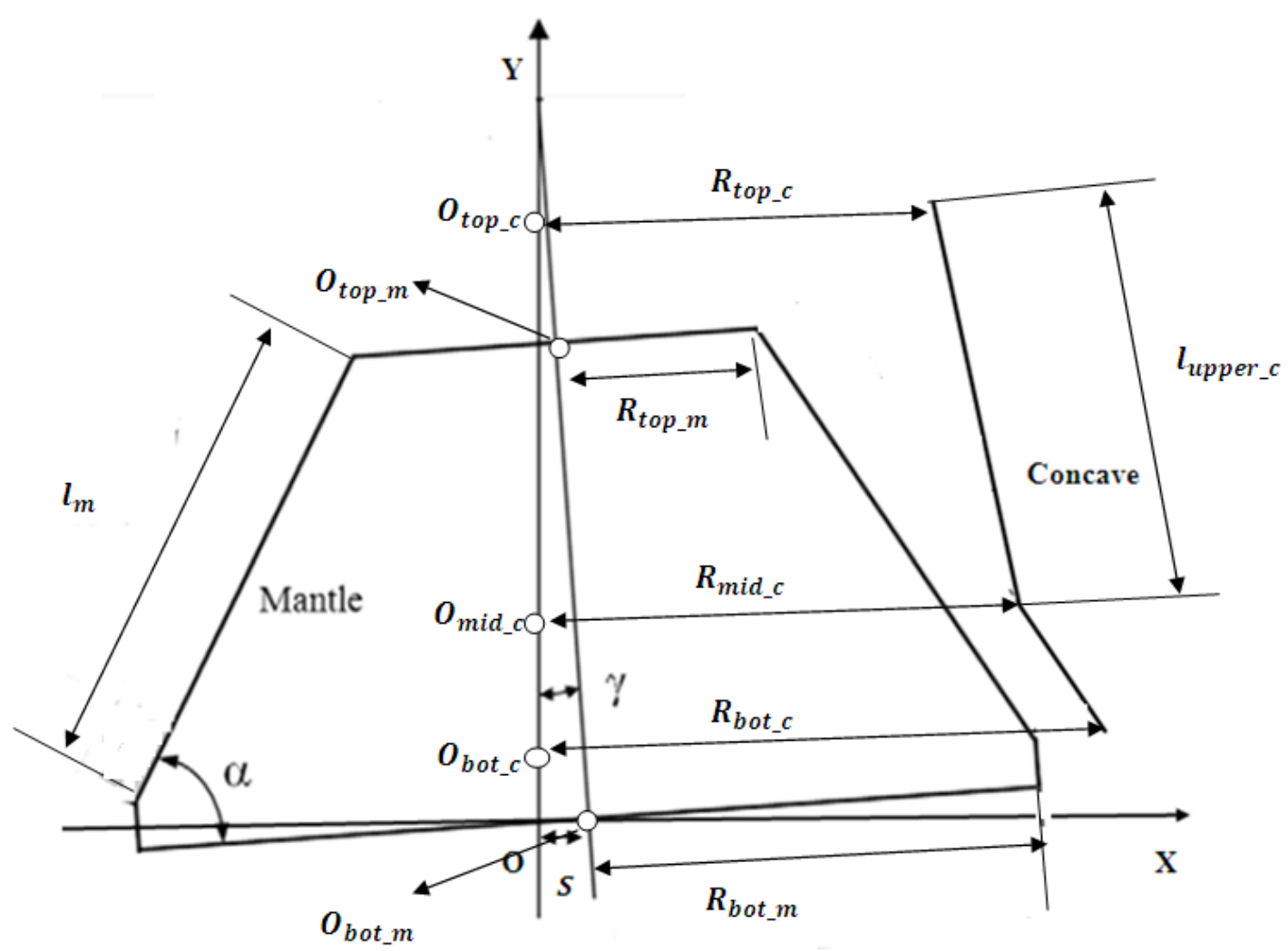

Figure 3. Parameters calculated in the DEM cone crusher model 


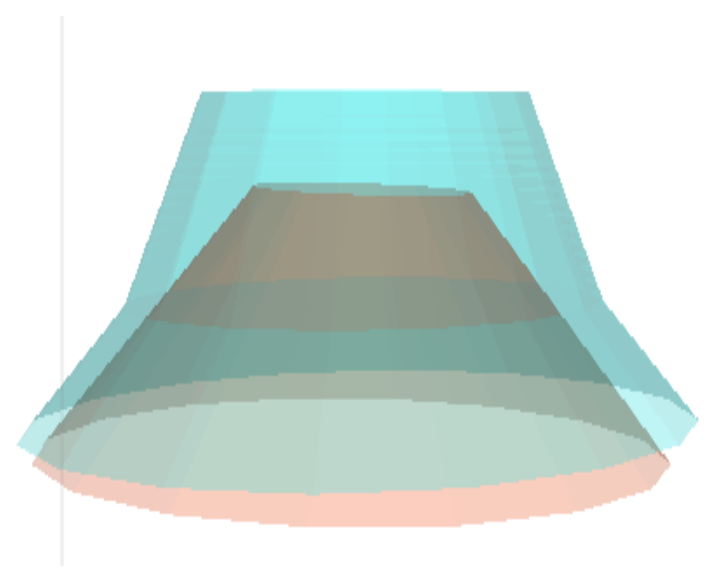

Figure 4. The DEM cone crusher model 


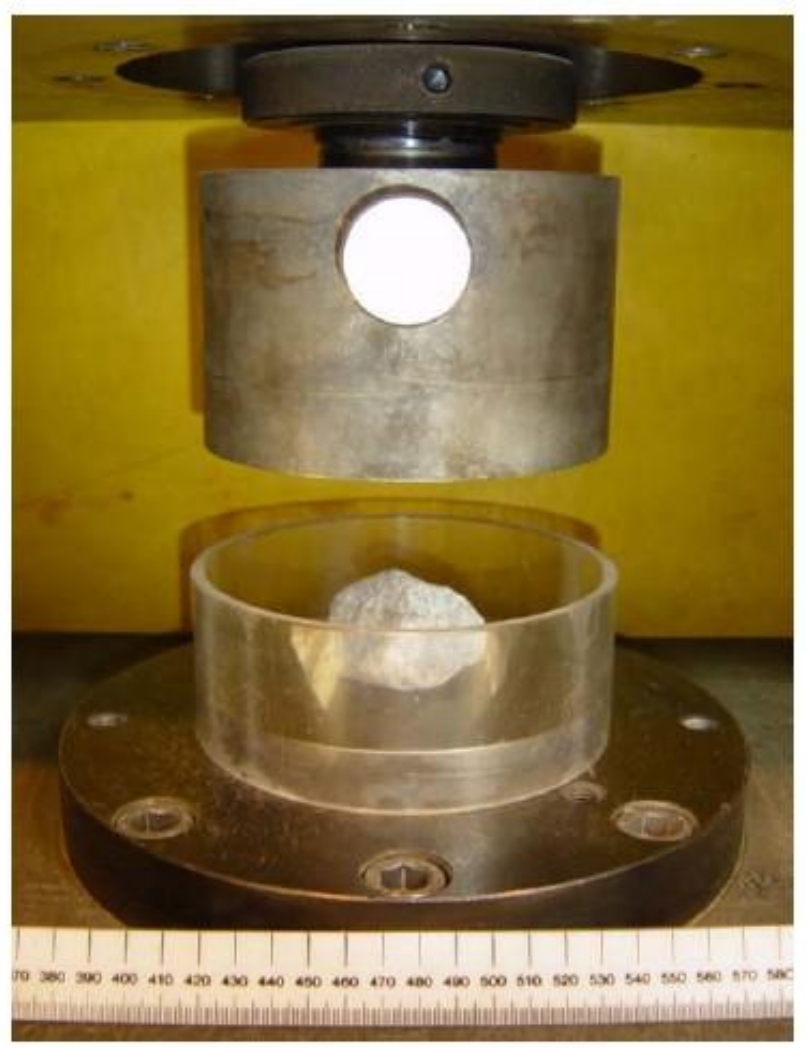

Figure 5 A photograph of the Zwick experimental testing rig used to apply diametrical compression tests to selected rock samples. 


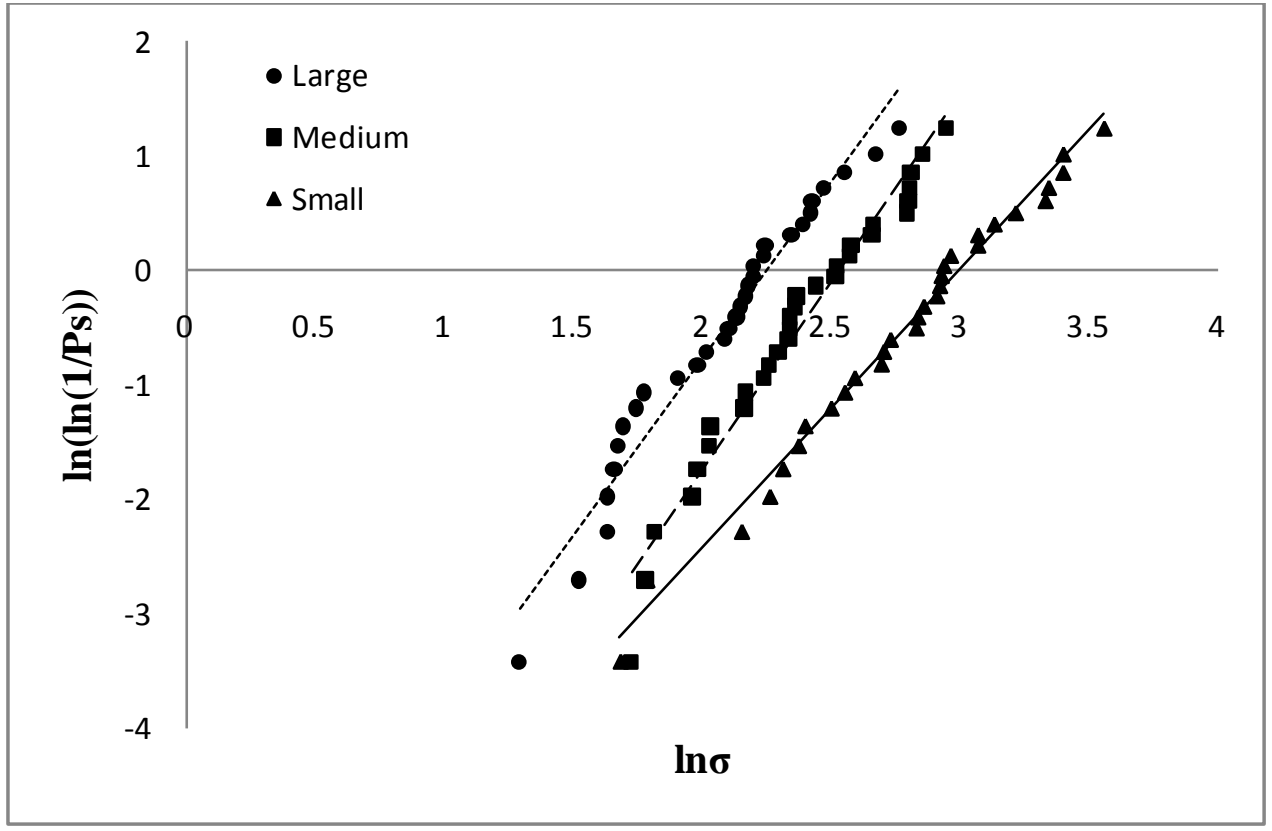

Figure 6 A plot of the computed Weibull survival probabilities for ballast particles of three size fractions

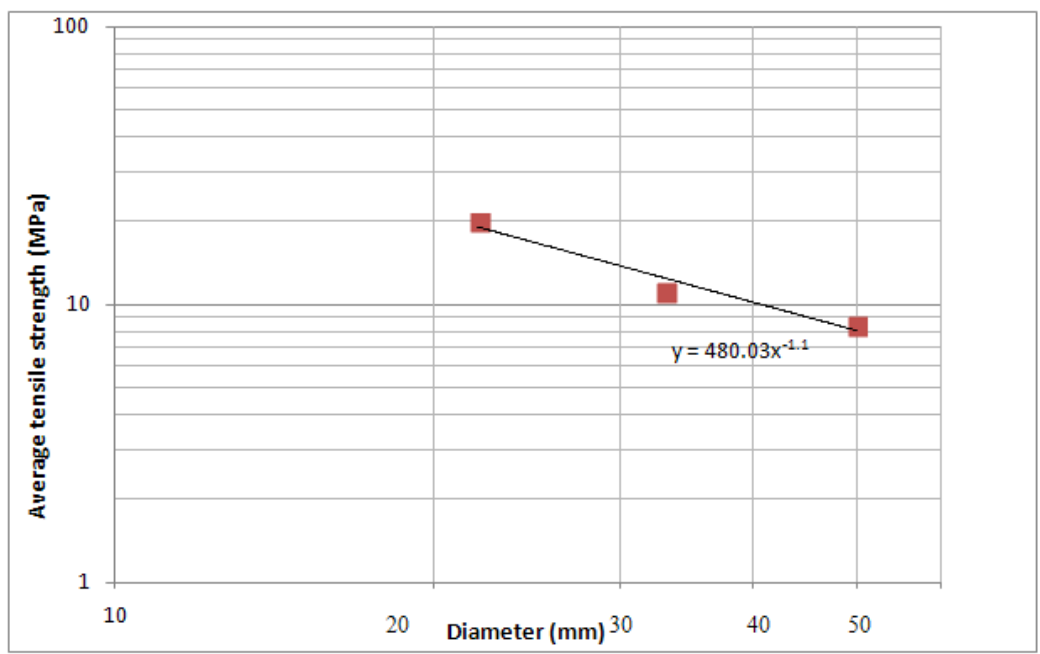

Figure 7 Average tensile strength against average particle size at failure 

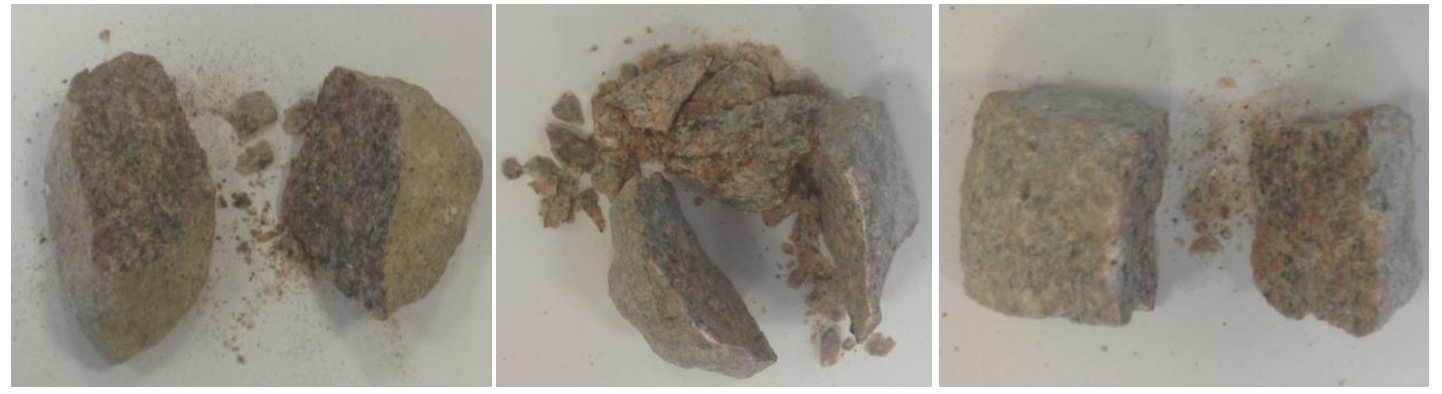

Figure 8 Photographs showing the typical daughter fragments produced following the failure of the single parent particles subjected to a diametrical compression test

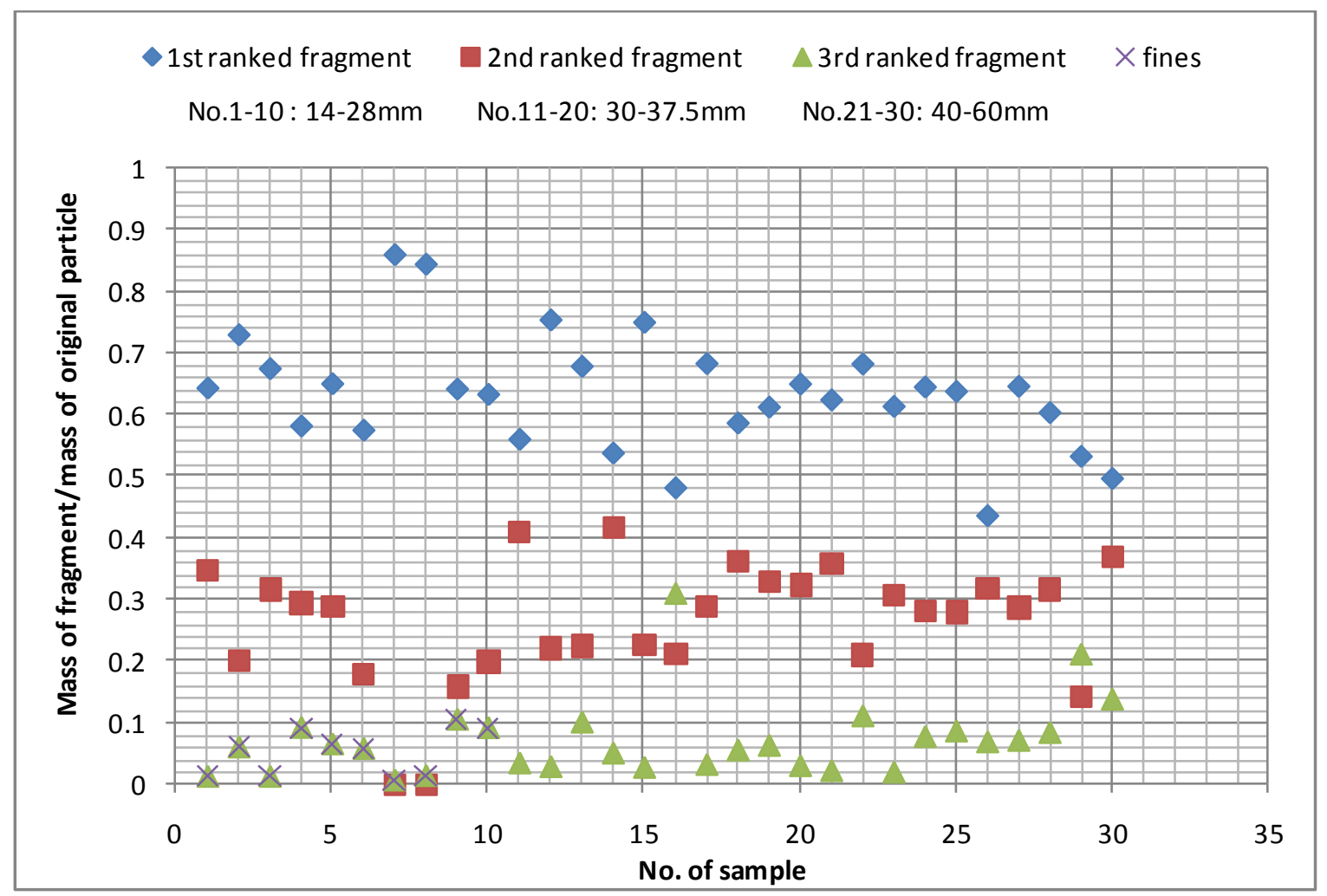

Figure 21A graphical presentation of the size and mass dassification data obtained from analyses performed on the fragments produced on the failure of particles subjected to a diametrical compression test 


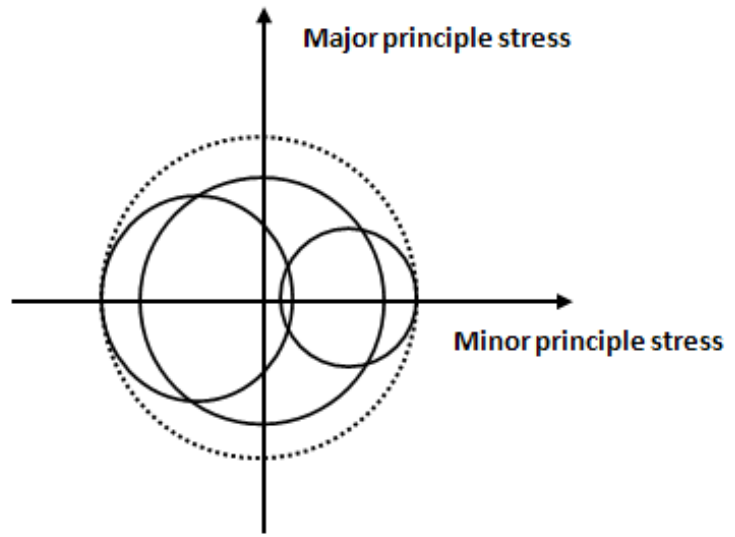

Figure 10. Triple split mechanism 


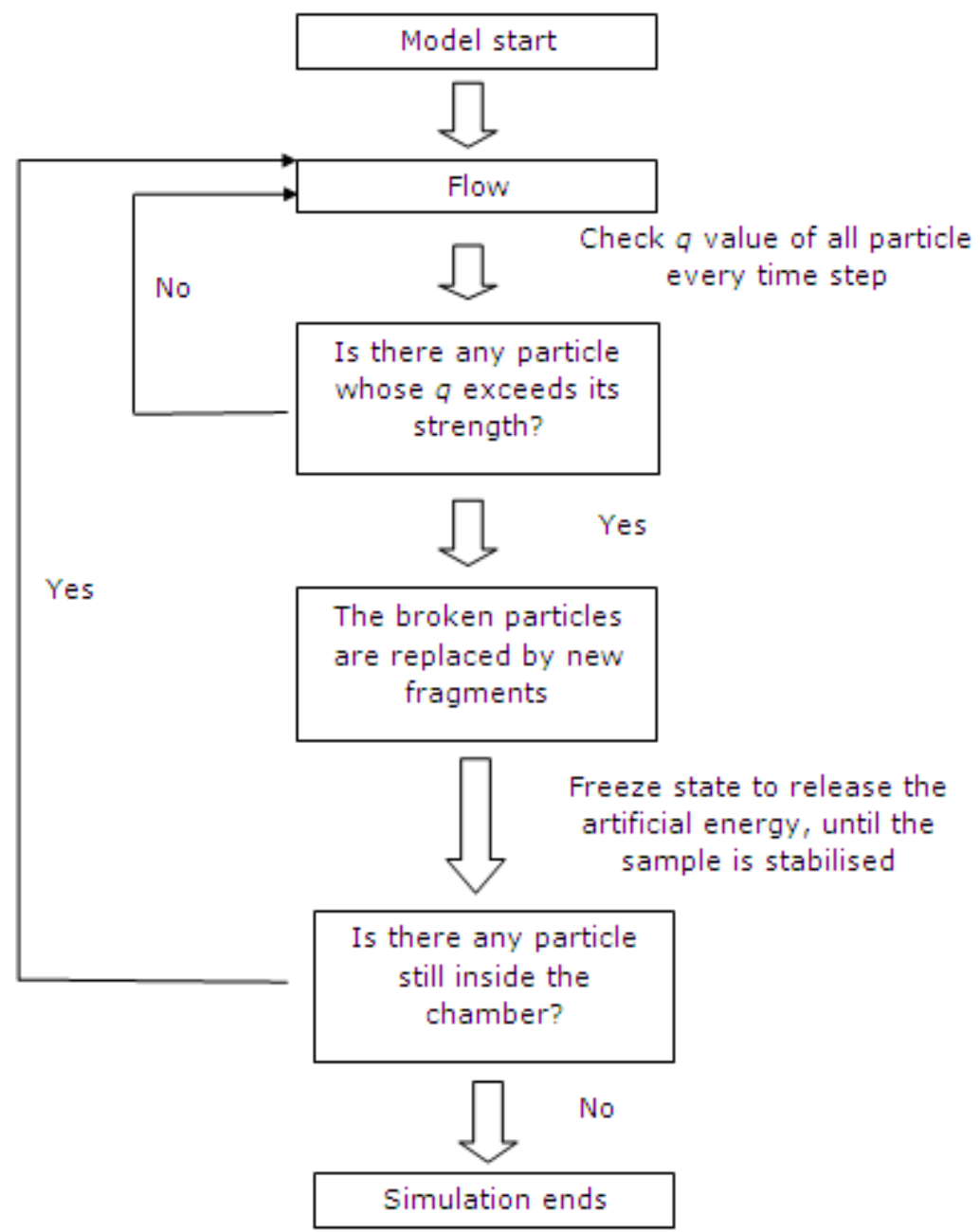

Figure 11, Flow chart of the cone crusher solution algorithm using the PRM model approach 

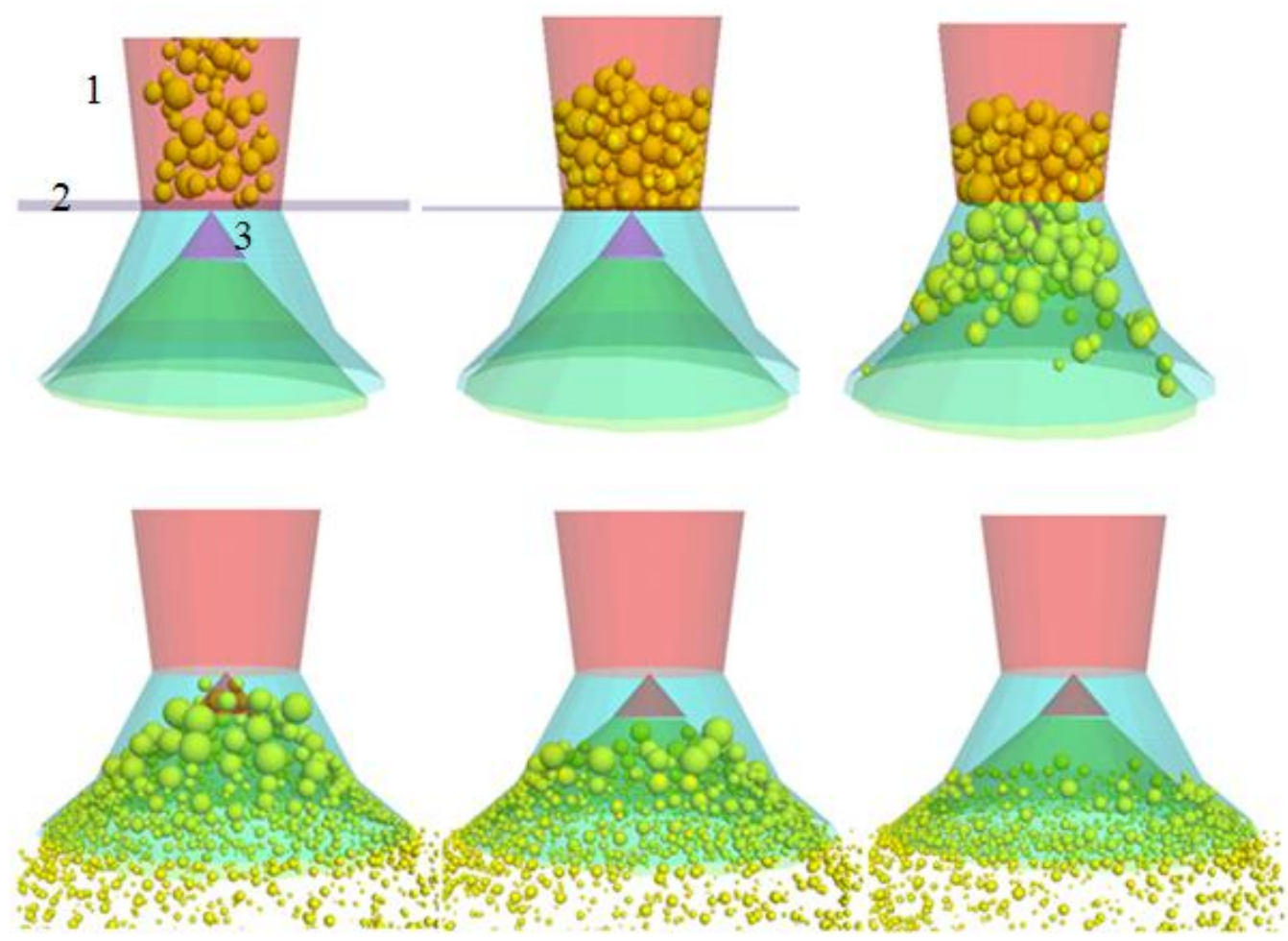

Figure 12. A sequence of animation stills which represent the dynamic performance of the crusher predicted by the DEM model 


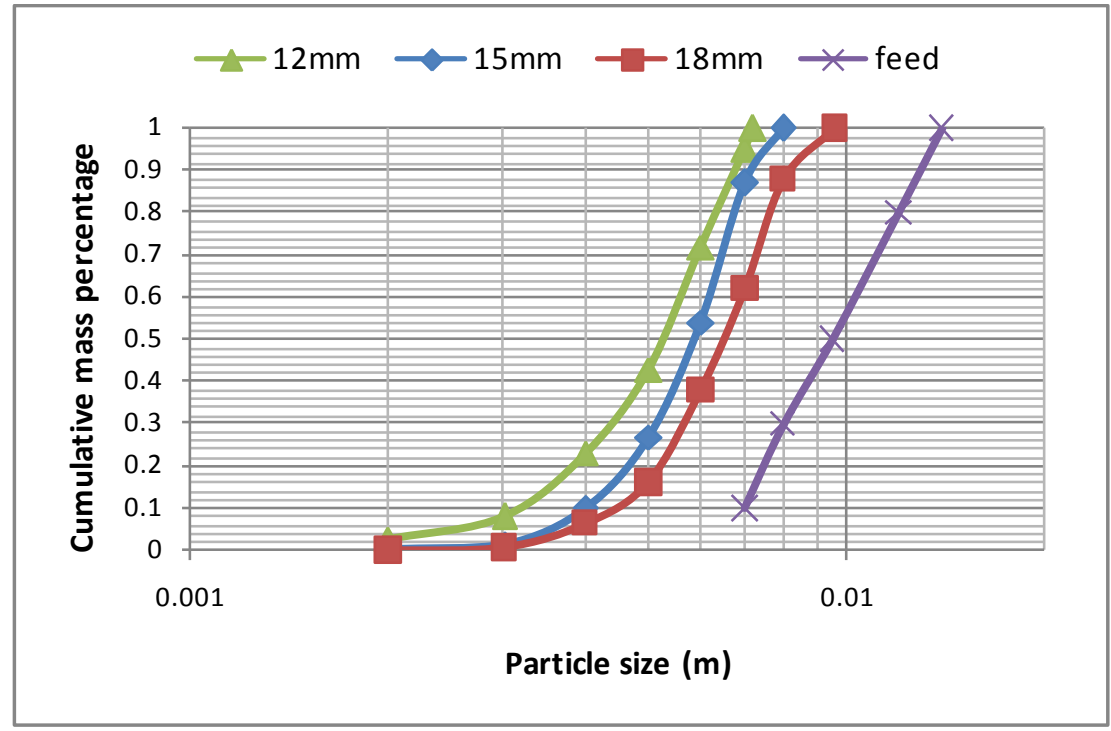

Figure 13 The effect of CSS on the size distribution of the products predicted by the DEM simulation

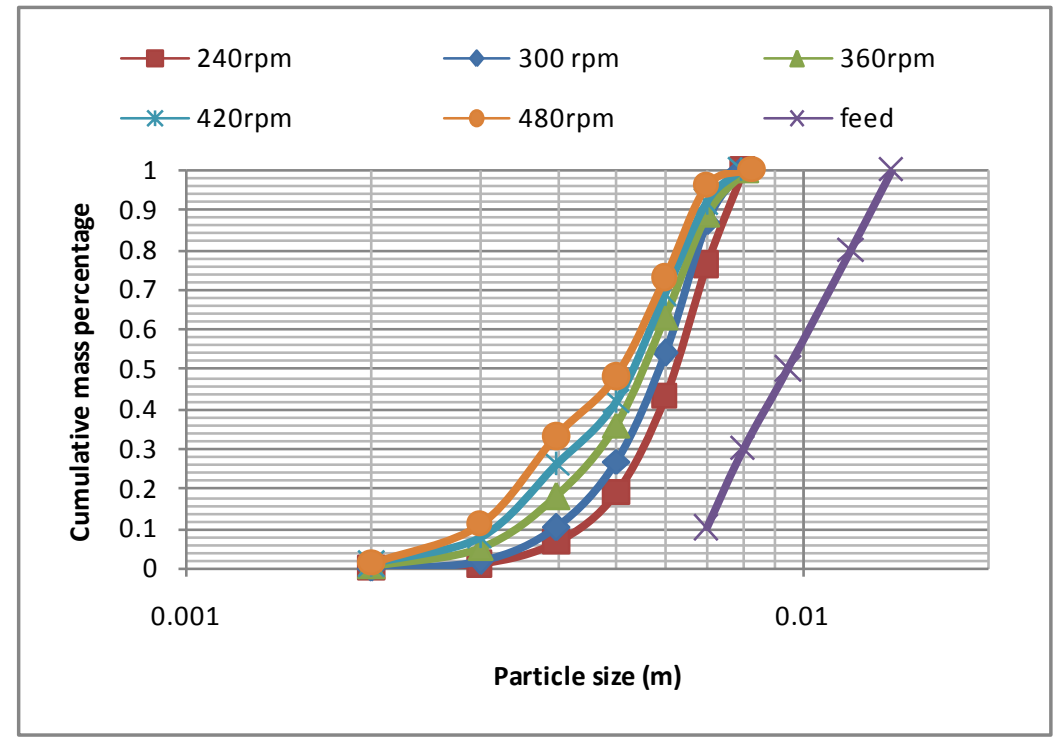

Figure 14. The effect of eccentric speed on size distribution of the size distribution of the products predicted by the DEM simulation 


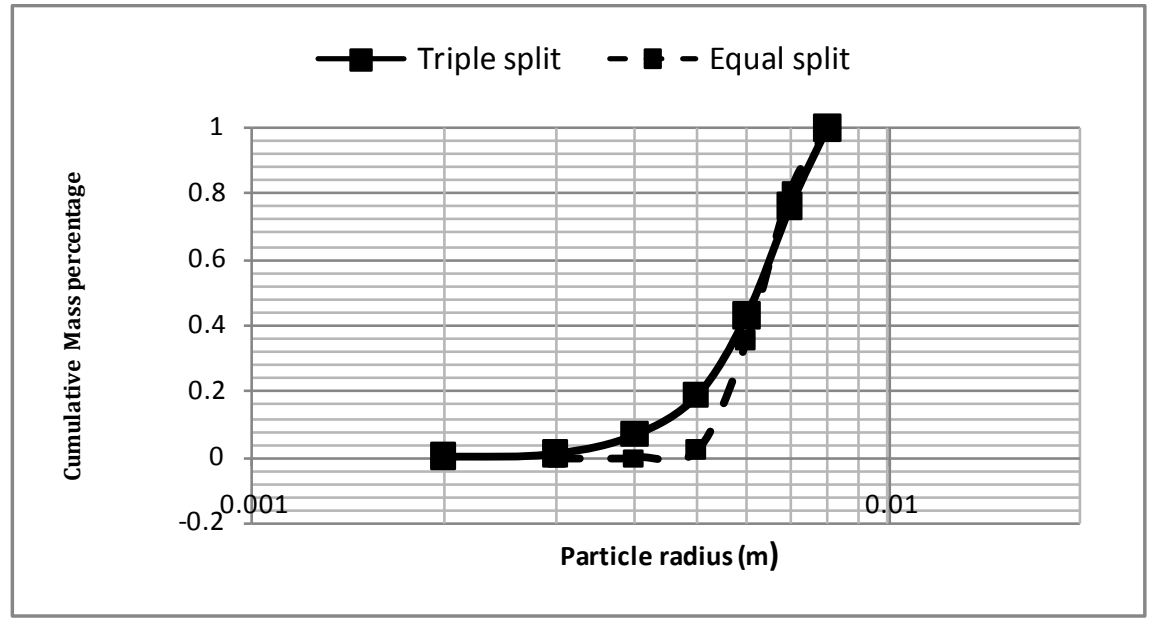

Figure 15. The effect of the breakage function on the size of the rock fragments formed

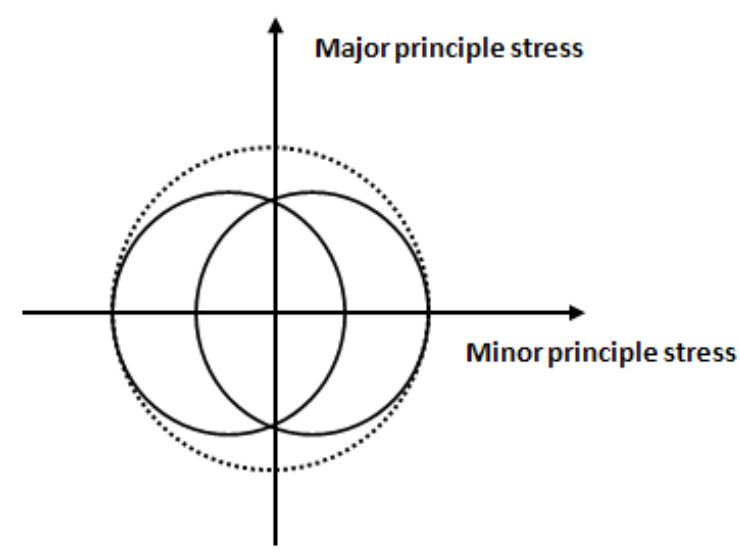

Figure 16. Equal split mechanism 


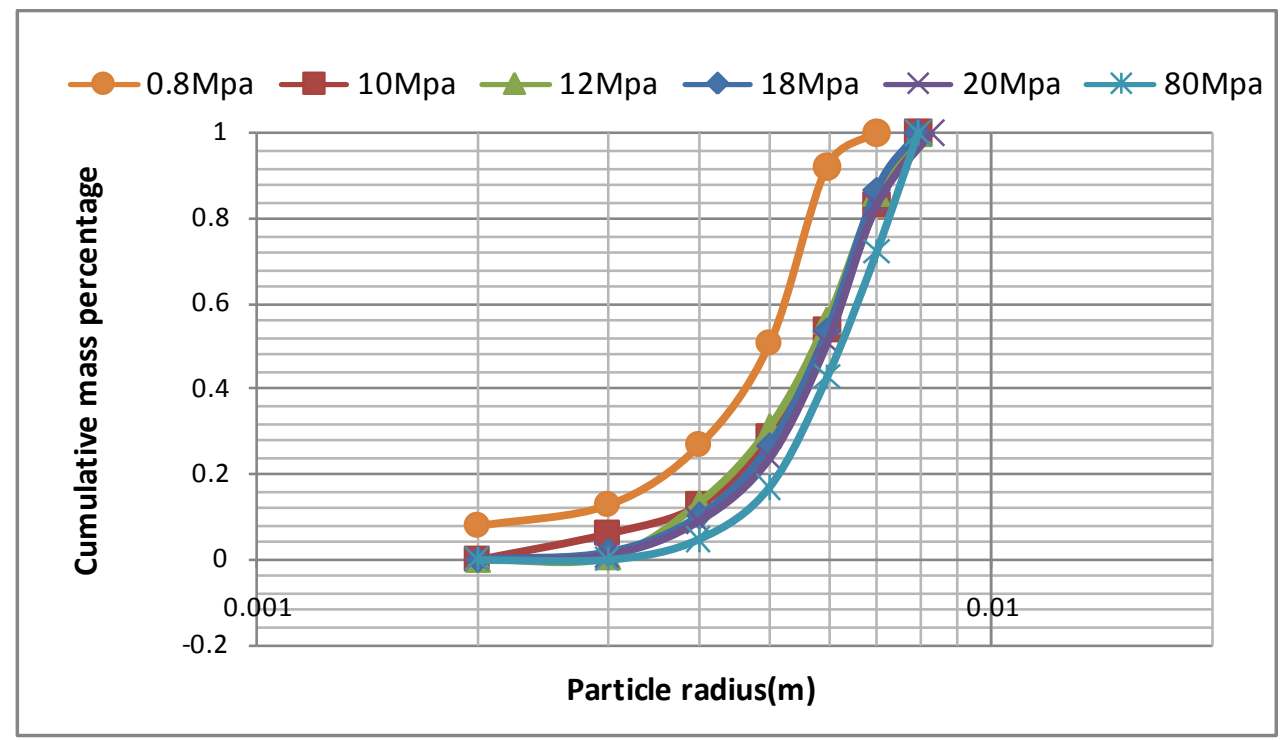

Figure 17. The effect of the values of the parameter $\sigma_{0}$ on the size distribution of the product stream

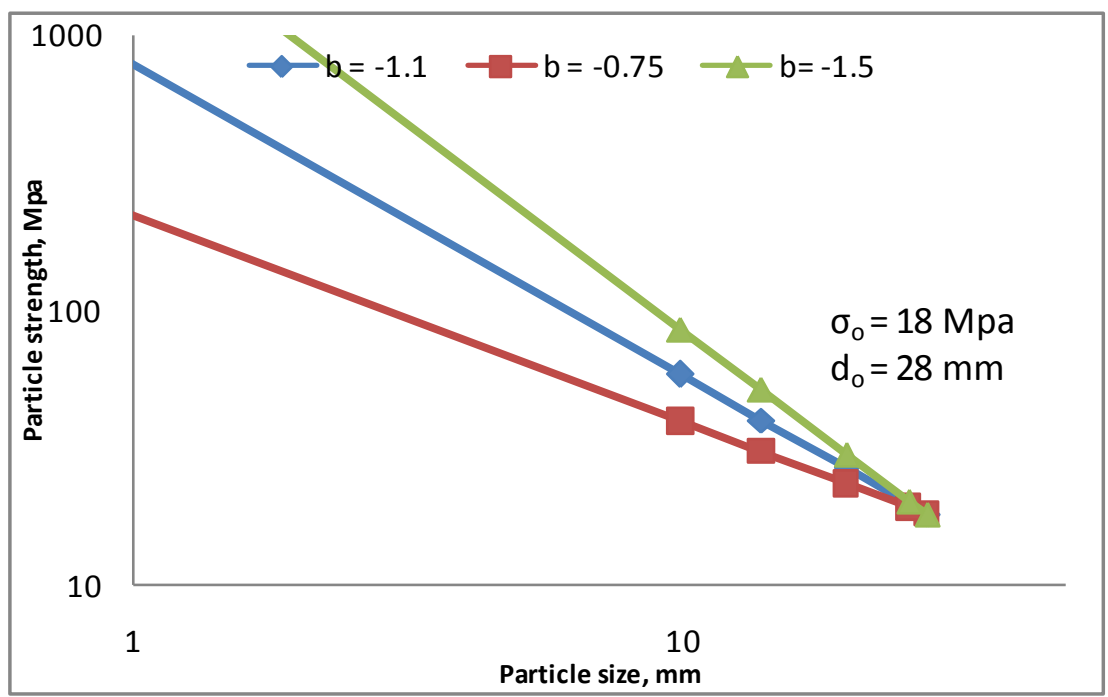

Figure 18. Particle strengths as a function for various values of the parameter $b$ with initial particle strength $18 \mathrm{Mpa}$ 


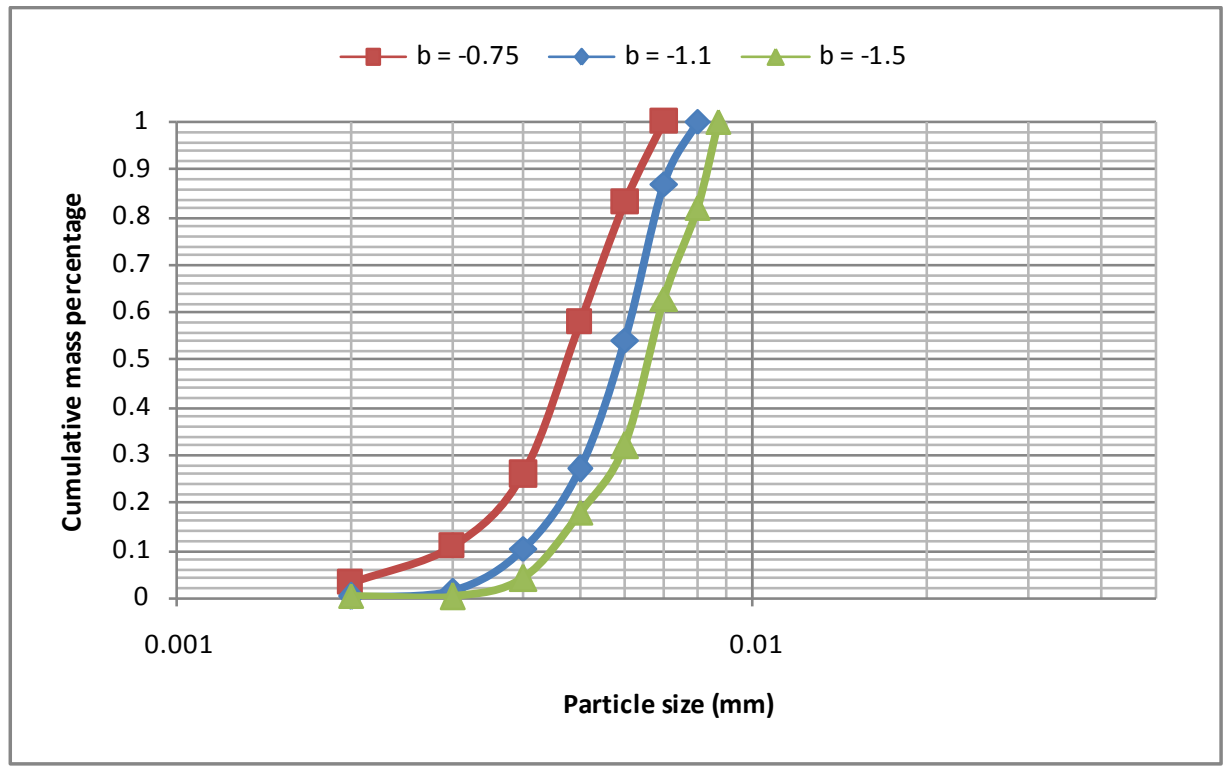

Figure 19. The effect of the parameter $b$ on the size distribution of products

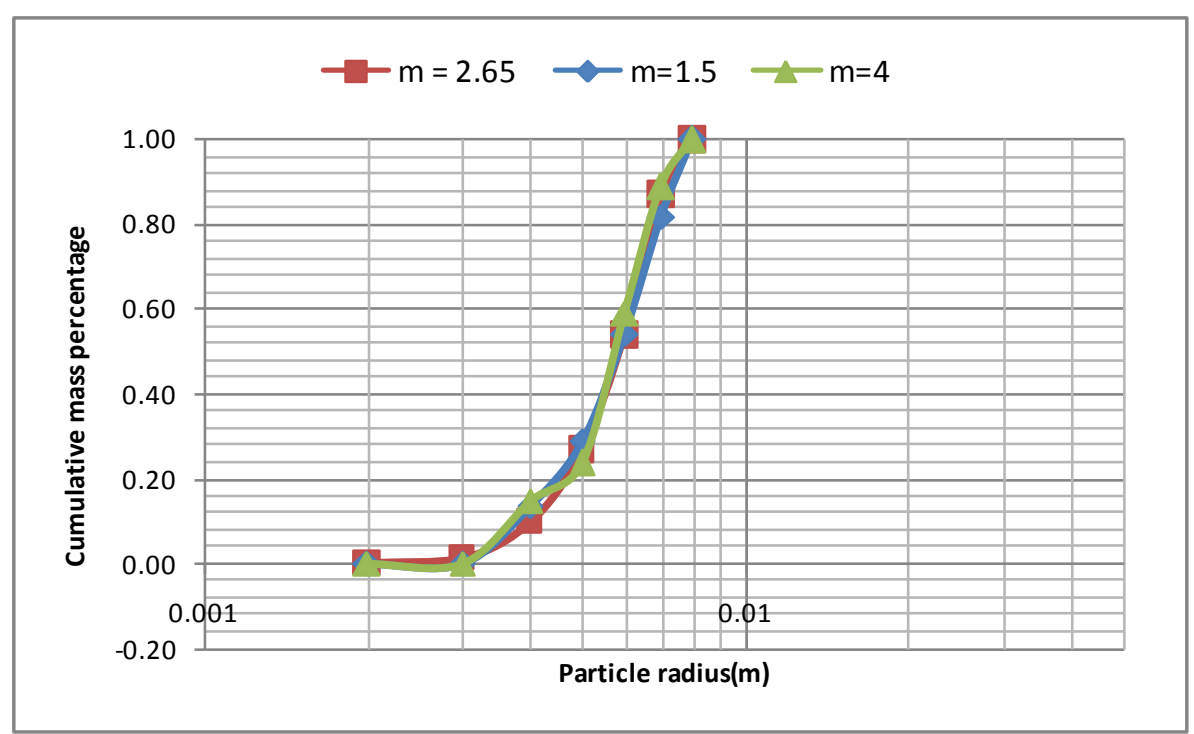

Figure 20. The effect of the parameter $m$ on the size distribution of products 